\title{
Influence of inhomogeneous porosity on effusion cooling
}

\author{
Gan Huang*, Li He \\ Department of Engineering Science, University of Oxford, Parks Road, Oxford OX1 3PJ, UK \\ *Corresponding author: huanggan9@hotmail.com
}

\section{Abstract}

Effusion cooling is an effective cooling technology which is considered as the next logical step of the cooling technology for gas turbine blades. Additive manufacturing technology makes it possible to fabricate effusion cooling structures in gas turbine blades with the optimal parameters and a low cost. However, the sizes of cooling holes were usually inhomogeneous owing to the limited accuracies of additive manufacturing technology. This study investigated the influence of inhomogeneous porosity on effusion cooling. The results showed that the inhomogeneous porosity dramatically affected the cooling effects of the surface film and the internal holes. However, the inhomogeneous porosity had a very slight effect on both global and local effusion cooling efficiency (less than 1\%) even when the non-uniformity reached 20\%. The intensive heat conduction inside the solid matrix played an important role for eliminating the adverse influence of the inhomogeneous porosity. Higher thermal conductivity, thicker thickness or narrower holes spacing both resulted in a smaller heat resistance and hence enhanced the heat conduction effect. However, the inhomogeneous porosity had a remarkable effect on effusion cooling efficiency when a low-thermalconductivity Thermal Barrier Coating (TBC) covered the surface. Decreasing the thermal conductivity of TBC would further aggravate the inhomogeneous problem. Key words: effusion cooling; additive manufacturing; inhomogeneous porosity 


\section{Introduction}

Increasing the turbine entry temperature (TET) of heavy-duty gas turbines or aeroengines contributes to improve the power generation and thermal efficiency. The turbine entry temperature has exceeded $2100 \mathrm{~K}$ which is in excess of the melting point of blade material and is keeping growth. Therefore, effective cooling technologies are essential to protect gas turbine blades for a higher efficiency and a longer lifetime [1]. Common cooling methods mainly include internal cooling and film cooling in present commercial applications. Film cooling has been proved to be a reliable and effective cooling method in practical working. However, discrete film holes can’t provide a full-coverage film on the blade surface which leads to an inhomogeneous cooling effect. The film cooling efficiency will even decrease when injecting excessive amount of coolant due to the detachment of film [2]. Effusion cooling has many rows of holes fully covered on the surface compared with film cooling. Effusion cooling could be considered as a special form of film cooling with full-coverage film holes. The film of effusion cooling fully and closely covers on the hot surface. In addition, the convective cooling through the internal holes is more intensive and sufficient owing to the large amount of holes. Therefore, full-coverage effusion cooling is considered as the next logical step of gas turbine blade cooling [3].

Effusion cooling was proposed in 1950s [4,5]. The fundamental researches of effusion cooling mainly focus on geometric parameters of holes, coolant/hot gas interaction and boundary layer development. A larger hole size leads to a higher cooling 
efficiency due to the reduced heat transfer coefficient of film [6]. Decreasing the hole diameter and simultaneously increasing their amount can also result in a higher cooling efficiency because of the less mixing effect [7]. Diffuser-shaped cooling hole gives a better film coverage and a higher cooling efficiency [8]. Effusion cooling efficiency increases with decreasing the spacing of holes because that the coolant jets merge together[9]. The experimental investigation has indicated that effusion cooling has a better cooling performance compared to film cooling [10]. However, manufacturing technology and cost of effusion cooling structure prevented its further practical applications [3]. The optimal parameters of effusion cooling structures have been discovered but manufacturability hindered their practical applications.

Additive Manufacturing (AM) is an emerging manufacturing technology, which has already brought new developing ideas to many fields. Additive manufacturing has advantages of economical cost and fabricating complex geometries compared to traditional subtractive manufacturing methods [11-13]. Additive manufacturing has been widely applied to biomaterial [14-15], aerospace [16-18], building [19, 20] and so on. Recently, additive manufacturing technology brought revolution in gas turbine industry [21-23]. SIEMENS has finished its first full load engine tests for gas turbine blades produced using Additive Manufacturing technology in the early of 2017 [24]. Additive manufacture technology enables complex and micro cooling structures for the gas turbine blades. Min et al. [10] and Huang et al. [25] successfully utilized additive manufacturing technology to fabricate metal samples with full-coverage micro-holes for transpiration/effusion cooling. Different shapes and distributions of micro-holes were 
fabricated and investigated to achieve a higher cooling efficiency and mechanical property. Blood-vessel-like [10] and tree-like [26] special-shaped cooling channels were manufactured to reduce the coolant flow resistance, which were difficult to be manufactured by the traditional manufacturing methods.

However, the accuracy of metal Additive manufacturing technology is still a limitation for precisely fabricating small cooling hole structures. Slice thickness, build orientation, material, and process parameters directly affect the manufacturing accuracy [27]. Metal additive manufacturing technology is based on melting metal powers by the focused laser beam. The diameter of the laser focus is about $0.1 \mathrm{~mm}$, which is close to the size of small effusion cooling holes. Unexpected metal particles will also be melted due to the heat diffusion effect around the laser focus. A large amount of tiny metal particles randomly adhered to the internal walls of cooling holes, which induced the random error of the small hole sizes [25]. In addition, impurities in coolant and combustion gas could partially block the small cooling hole during gas turbine working $[5,28]$, which finally changed the effective hole diameters. Therefore, the hole sizes would be inhomogeneous due to manufacturing error and impurity blockage as shown in Fig.1. However, previous studies of effusion cooling mainly based on ideal homogeneous porosity. There is little literature investigated the influence of inhomogeneous porosity on the flow and heat transfer in effusion cooling, which is important for practical applications but the interaction is still unclear. 


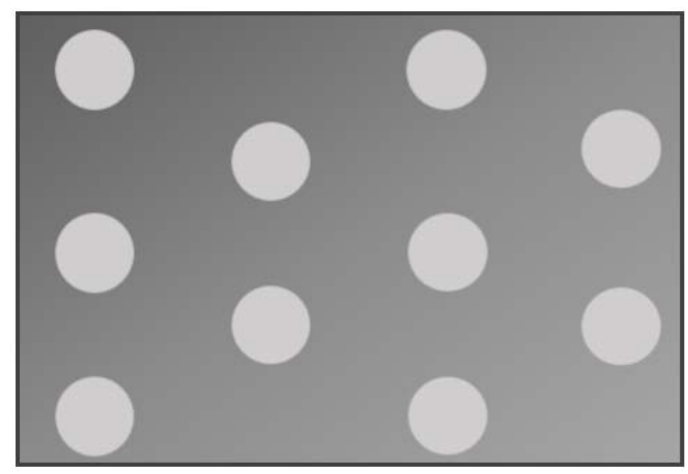

(a) Ideal designed porous sample with homogeneous porosity

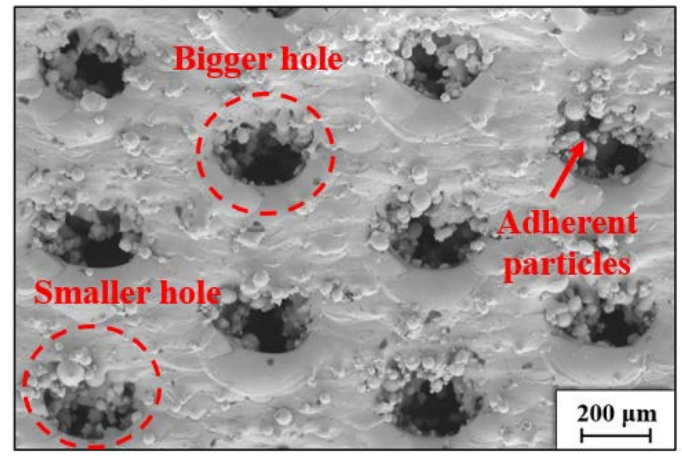

(b) Actual additive manufactured porous sample with inhomogeneous porosity

Figure 1. Caparison of ideal and actual additive manufactured porous sample with cooling holes

Here, we investigated the influence of inhomogeneous porosity on effusion cooling effect. Different non-uniformities and random distribution ways of cooling holes were modeled and simulated. This study also investigated the effects of solid thermal conductivity, plate thickness, spacing of holes and Thermal Barrier Coatings (TBC) on effusion cooling efficiency with an inhomogeneous porosity.

\section{Numerical method}

This study investigated the effusion cooling for porous plates with inhomogeneous porosities. The geometry parameters of the porous plates were defined as shown in Fig. 
2. $H$ is the thickness in $z$ direction, $W$ is the width in $y$ direction, $L$ is the length in $x$ direction. The mainstream flows along the $x$ positive direction upon the porous surface. Effusion cooling holes fully distributed in the porous plate with the same spacing of $\Delta$. Each hole was marked by the customized coordinate system of $i$ and $j . D_{\mathrm{i}, \mathrm{j}}$ is the diameter of a certain hole.

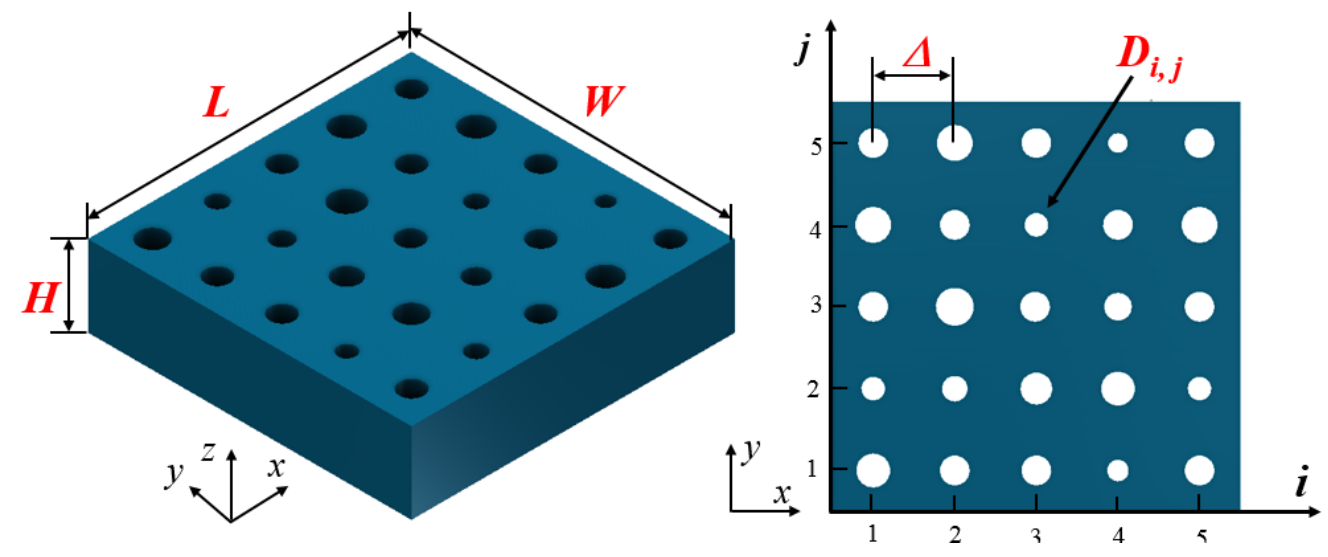

Figure 2. Porous plate with inhomogeneous porosity

As shown in Fig. 1, the actual hole diameters, $D_{\mathrm{i}, \mathrm{j}}$, always deviated from the designed ideal value, $D_{0}$, due to additive manufacturing error. The relationship of $D_{\mathrm{i}, \mathrm{j}}$ and $D_{0}$ was defined as:

$$
D_{i, j} \in \operatorname{Random}\left(\left[D_{0}(1-\delta), D_{0}(1+\delta)\right]\right),\left(1 \leq i \leq N_{x}, 1 \leq j \leq N_{y}\right)
$$

For an extreme instance, the diameters of holes are homogeneous when $\delta=0 \% . \delta$ is named as non-uniformity hereinafter in this paper. $N_{x}$ and $N_{y}$ are the numbers of rows in the $x$ and $y$ directions. In order to simulate the random situations in practical applications, the detail values of $D_{\mathrm{i}, \mathrm{j}}$ were generated by the function of random number generation in MATLAB within the range of Eq. (1). In this study, we defined and simulated over ten models with different geometric parameters to investigate the effects of non-uniformity, thickness, spacing of holes and TBC. The detail values of the geometric parameters 
would be declared in hereinafter corresponding sections.

Figure 3 shows the 3D physical model of effusion cooling simulated in this study. The porous plate zone was conjugated with the coolant zone and hot mainstream zone. The hot air , acted as the mainstream, blew in parallel with the porous plate surface in $x$ positive direction. The cold coolant air flowed through the effusion holes and then injected into the mainstream. The height of the mainstream is $30 \mathrm{~mm}$ and its width was the same with the porous plate. The physical properties of the solid were defined as the same as Inconel 718, which was a common material of additive manufacturing. The mainstream temperature was $1000 \mathrm{~K}$ and its velocity was $100 \mathrm{~m} / \mathrm{s}$. The coolant temperature was $300 \mathrm{~K}$ and the mass flow rate was calculated according to the coolant injection ratio $F$, which was defined as [29-31]:

$$
F=\frac{\rho_{c} V_{c}}{\rho_{\infty} V_{\infty}}
$$

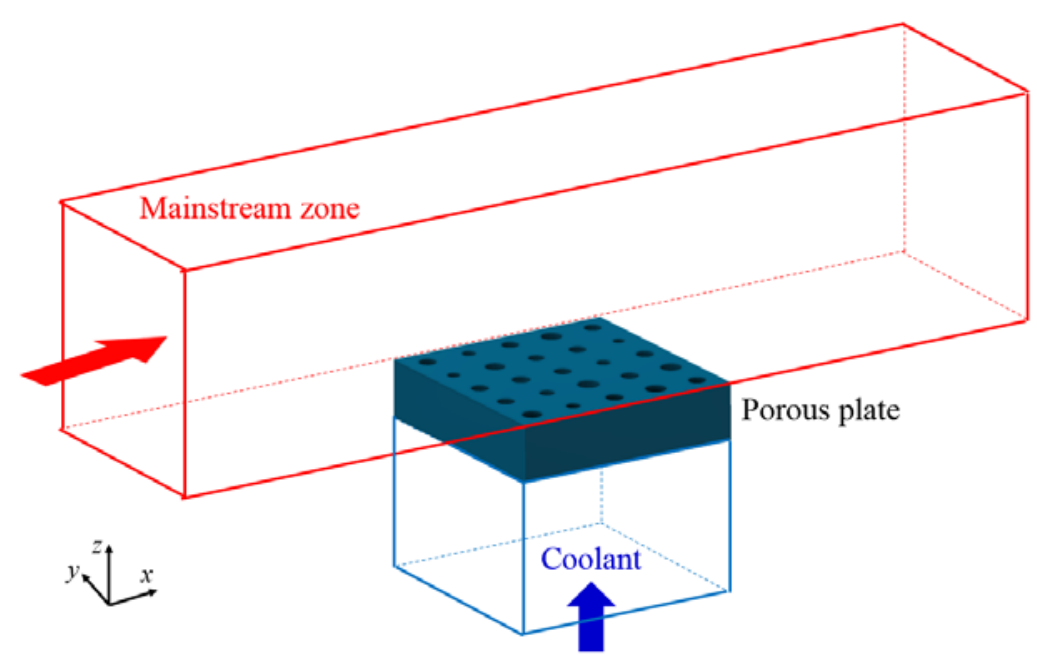

Figure 3. Physical model of effusion cooling

The mainstream and coolant are compressible flow. The steady Reynolds-averaged Navier-Stokes equations and energy equations were solved using ANASYS FLUENT 
19.2 solver:

$$
\begin{gathered}
\frac{\partial}{\partial x_{\mathrm{i}}}\left(\rho u_{\mathrm{i}}\right)=0 \\
\frac{\partial\left(\rho u_{\mathrm{i}} u_{\mathrm{j}}\right)}{\partial x_{\mathrm{i}}}=-\frac{\partial P}{\partial x_{\mathrm{i}}}+\frac{\partial \tau_{\mathrm{ij}}}{\partial x_{\mathrm{j}}} \\
\frac{\partial}{\partial x_{\mathrm{i}}}\left(u_{\mathrm{i}}(\rho E+P)\right)=\nabla\left(\lambda \frac{\partial T}{\partial x_{\mathrm{i}}}+u_{\mathrm{j}} \tau_{\mathrm{ij}}\right)
\end{gathered}
$$

where $E$ is the total energy, $E=h+u^{2} / 2-P / \rho$. The "density based" model was applied to solve the non-linear governing equations with the "ideal gas model" for the fluid. Standard $k-\varepsilon$ turbulence model was used for the turbulence. The previous study showed that the Standard $k-\varepsilon$ model gives good simulation results for transpiration/effusion cooling in the subsonic flow [25]. The mainstream inlet was set as "Velocity inlet" and the coolant inlet was set as "mass flow inlet". The two sides of the model were set as periodic boundary.

The effusion cooling efficiency, $\eta$, was defined as [29]:

$$
\eta=\frac{T_{\infty}-T_{w}}{T_{\infty}-T_{c}}
$$

The meshes of the calculation model were created by ANASYS ICEM. This study investigated ten models with different geometric parameters. These ten models then produced corresponding ten sets of meshes. A same method of meshing was used for all these twenty sets of meshes. The grid independence investigations were then conducted. For instance, Fig. 4 shows the meshes of the calculation model with $H=5 \mathrm{~mm}, D_{0}=1$ $\mathrm{mm}, \delta=20 \%$, and $\Delta=4 \mathrm{~mm}$. The left of Fig. 4 is the global view, while the right one is the local section view of the porous plate zone. The elements concentrated near the plate 
surfaces, holes walls, mainstream walls. Grid independence was investigated as shown in Fig. 5. The initial grid had about 0.58 million hexahedral elements. The mesh was then refined to 1.42 million and 3.22 million by densifying the mesh near the holes, porous plates and mainstream wall, where had significant gradients of temperature or velocity. Figure 5 shows the lateral average temperature distributions on the porous surfaces for these three different grids. The grid with 1.43 million hexahedral elements was finally chosen for the simulation to balance calculation accuracy and calculation cost. $\mathrm{y}^{+}$on the plate wall was around 1.
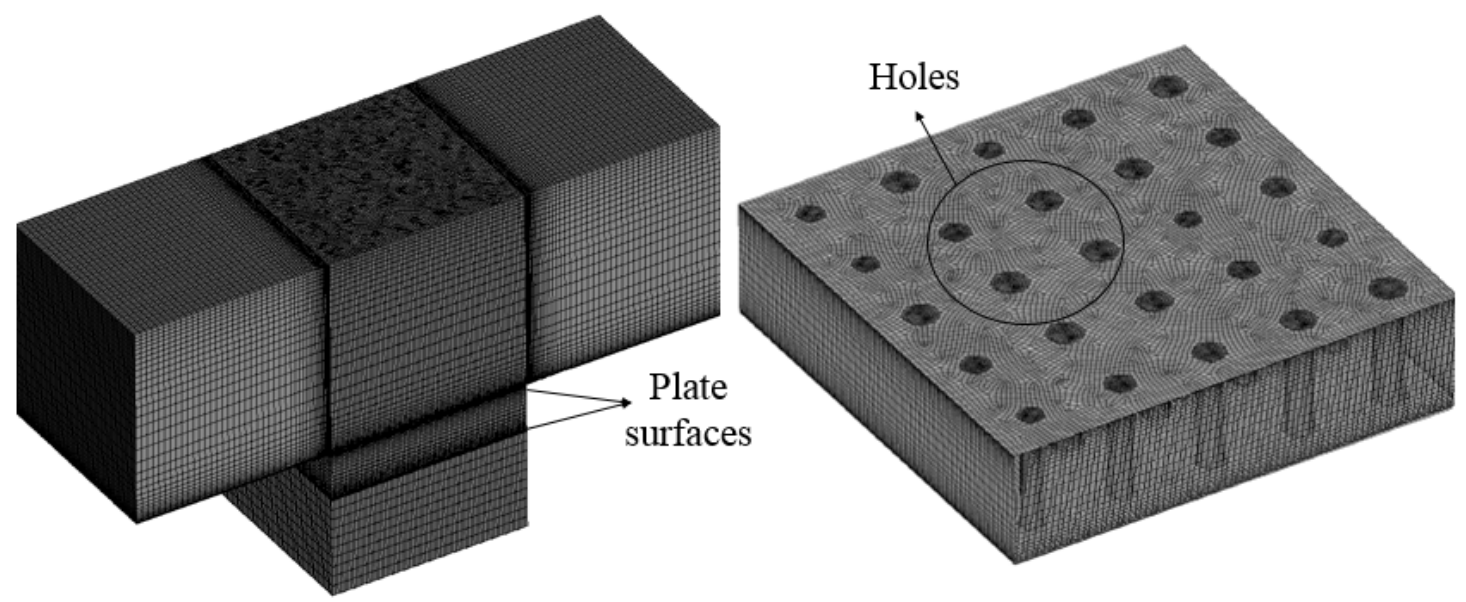

Figure 4. Meshes of the calculation model

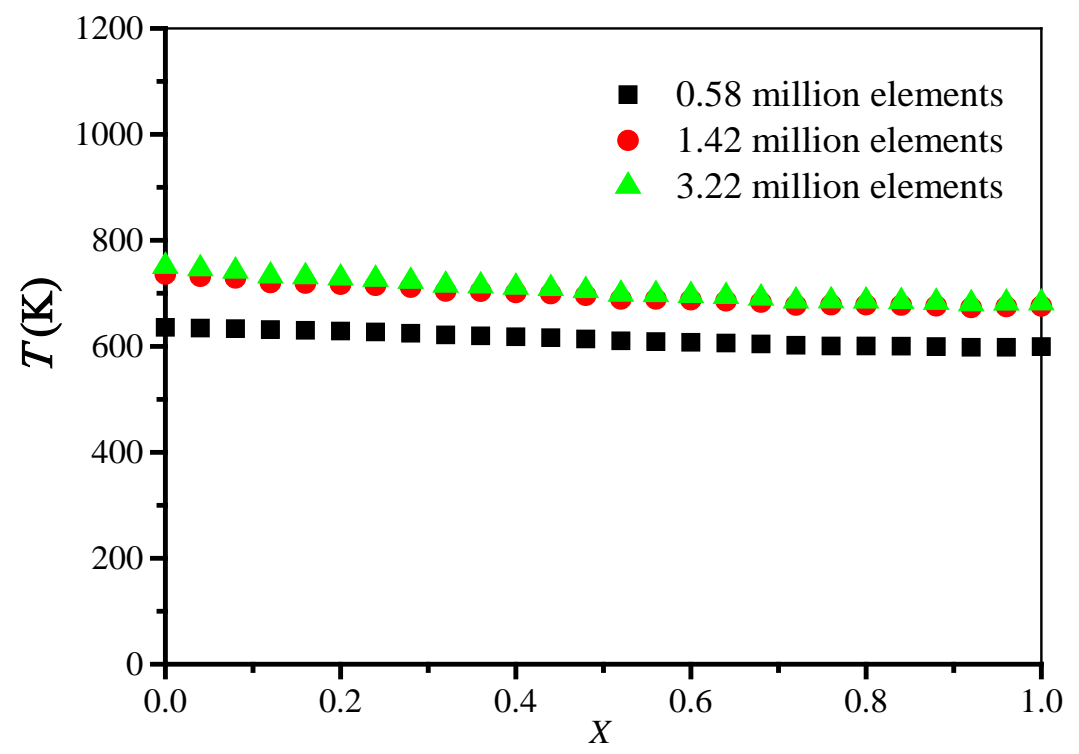


Figure 5. Grid independence investigation

The reliability of the numerical method has been validated by comparing with the experimental data of effusion cooling [25] as shown in Fig. 6. The boundary conditions, physical properties of, geometric parameters were kept the same with those of the experiment. The numerical results corresponded well with the experimental results which considered experiment error. The heat conduction between the porous plate and the wind tunnel wall was ignored in the current numerical model, thus the simulated cooling efficiencies in the leading and trailing boundaries of porous plate inevitably slightly deviated from the experimental data. But overall, this numerical model accurately predicted the effusion cooling efficiency distributions. The average cooling efficiency of the simulation was $56.0 \%$, which was close to the experimental result of 55.8\%. The above numerical model was then reliably used to simulate effusion cooling in this study.

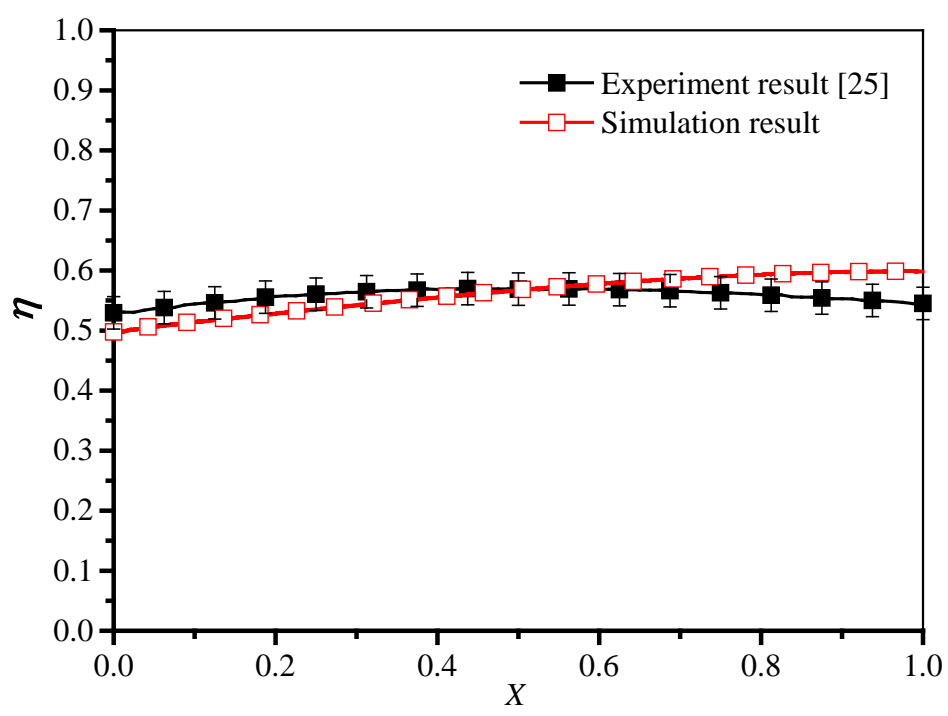

Figure 6. Comparison of the simulation and experiment result 


\section{Results and analysis}

\subsection{The cooling efficiencies with different non-uniformities}

Figure 7 shows the effusion cooling efficiency distributions for three different nonuniformity $\delta=0 \%, 20 \%$ and $50 \%$. The coolant injection ratio was $F=1 \%$. The blowing ratio was 0.20 for $\delta=0 \%$ when the injection ratio was $1 \%$ according to the hole area and the definitions described in detail by Min et al. [10].The case of $\delta=0 \%$ shows the cooling efficiency with an ideal homogeneous porosity. The hot mainstream flows from left to right. The coolant film covered on the porous surface and then accumulated to be thicker and thicker along the mainstream direction. Thus, the cooling efficiencies gradually increased along the mainstream direction. The cooling efficiency periodically distributed along the $y$ direction when $\delta=0 \%$. However, the porous plate with $\delta=20 \%$ suffered inhomogeneous cooling efficiency distributions. A larger hole resulted in a higher cooling efficiency nearby. This inhomogeneous phenomenon became more significant when the non-uniformity increased from $20 \%$ to $50 \%$. The cooling efficiency distributions for $\delta=50 \%$ more clearly shows a positive correlation between the hole size and its surrounding cooling efficiency.

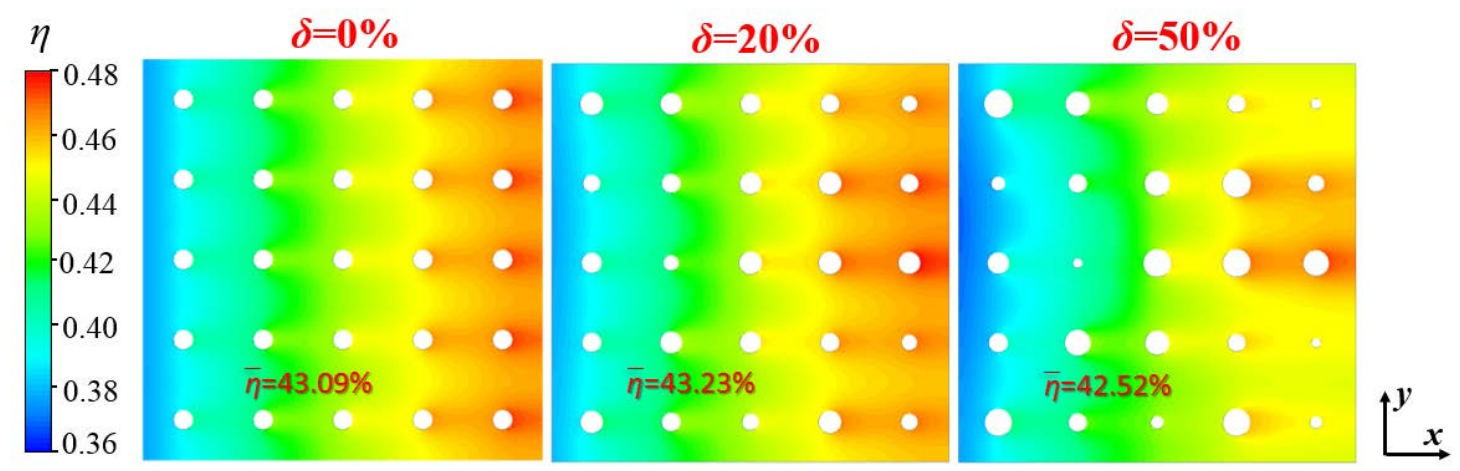

Figure 7. Cooling efficiency distributions for different non-uniformities

The average cooling efficiencies on the whole porous surfaces for $\delta=0 \%, 20 \%$ and 
50\% were $\bar{\eta}=43.09 \%, 43.23 \%$ and $42.52 \%$ respectively. The numerical results showed that the inhomogeneous porosity had a slight influence on average cooling efficiency when $\delta=20 \%$. The absolute difference of average cooling efficiency between $\delta=0 \%$ and $20 \%$ was only $\Delta \bar{\eta}=0.14 \%$. The inhomogeneous porosity had a more significant influence on cooling efficiency when $\delta=50 \%$. However, the difference of average cooling efficiency was also only $\Delta \bar{\eta}=0.57 \%$ when $\delta=50 \%$. The inhomogeneous porosity had a very slight influence on average effusion cooling efficiency even when the non-uniformity reached $50 \%$.

Figure 8 shows the local difference distributions of the cooling efficiency $\Delta \eta$, which was defined as:

$$
\Delta \eta=\left|\eta_{\delta}-\eta_{0}\right|
$$

Since the geometries for $\delta=0 \%, 20 \%$, and $50 \%$ were not strictly the same, null values received surround the smaller holes when locally subtracting. The smaller holes of $\delta=20 \%$ and $50 \%$ were marked with red dotted circles as shown in Fig.8, while the rest unmarked holes were the bigger ones. The maximum local absolute different values between $\delta=20 \%$ and $0 \%$ was only $\Delta \eta_{\max }=0.81 \%$, while the maximum local absolute different values between $\delta=50 \%$ and $0 \%$ increased to $\Delta \eta_{\max }=2.43 \%$. The inhomogeneous porosity had a slight effect on local cooling efficiency when the nonuniformity was $20 \%$. However, the inhomogeneous porosity had a more significant effect on local cooling efficiency when increasing the non-uniformity. 


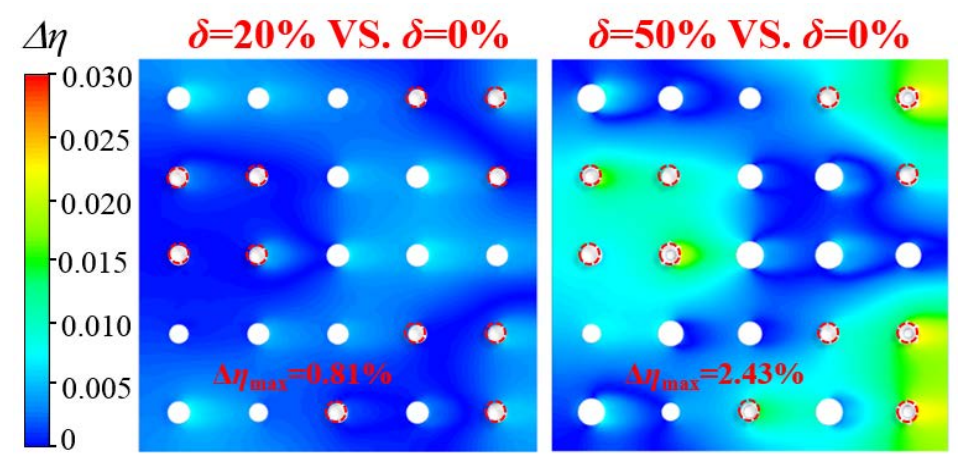

Figure 8. Local absolute difference distributions of cooling efficiency

Figure 9 shows the cooling efficiency distributions of $\delta=20 \%$ and $50 \%$ with three different random distribution ways. The effusion cooling with different random distribution ways of inhomogeneous porosity were simulated to investigate the sensitive of the random distribution ways. The porous plates for $\delta_{1-1}, \delta_{1-2}$ and $\delta_{1-3}$ had the same non-uniformity of $20 \%$ but had different random distribution ways for holes. The porous plates for $\delta_{2-1}, \delta_{2-2}$ and $\delta_{2-3}$ had the same non-uniformity of $50 \%$. Table 1 shows the relative change of the opening area (hole area) $\Delta A_{\mathrm{h}}$, the average cooling efficiencies $\bar{\eta}$, the differences of average cooling efficiencies $\Delta \bar{\eta}$, and the maximum differences of local cooling efficiency $\Delta \eta_{\max }$ between inhomogeneous and homogeneous porous plates for the different random distribution ways. Figure 9 and Table 1 show that the inhomogeneous porosity had a very slight effect on global average cooling efficiency for different random distribution ways. The average cooling efficiencies of $\delta_{1-1}, \delta_{1-2}, \delta_{1-}$ ${ }_{3}, \delta_{2-1}, \delta_{2-2}$ and $\delta_{2-3}$ were both close to that of $\delta_{0}$ and their absolute differences $\Delta \bar{\eta}$ were less than $1 \%$. The inhomogeneous porosity had a slight effect on local cooling efficiency when the non-uniformity was $20 \%$ while the maximum absolute local differences $\Delta \eta_{\max }$ were also both less than $1 \%$. The non-uniformity had a random influence on the opening area of the sample. The blowing ratio changed with different non-uniformities owing to 
the changes of the total opening areas.

The numerical results already showed that the inhomogeneous porosity had a very slight influence on effusion cooling when the inhomogeneity was $20 \%$. The inhomogeneity would definitely have a less influence if the inhomogeneity was less than $20 \%$, so this study didn't further investigate the case with an inhomogeneity less than 20\%. The current commercial additive manufacturing machines (Arcam ${ }^{\circledR}$, Concept laser $^{\circledR}$, EOS $^{\circledR}$, SLM Solutions ${ }^{\circledR}$ ) have an overall precision below $0.14 \mathrm{~mm}$ [32]. The geometrical accuracies of the 3D-printed holes in this study would be controlled less than $20 \%$ by current commercial additive manufacturing machines, so we didn’t further investigate the inhomogeneity between $20 \%$ and $50 \%$ in this study. The next sections of this study put more efforts on revealing the mechanism and the influences of thermal conductivity and TBC based on the case of $\delta=20 \%$.

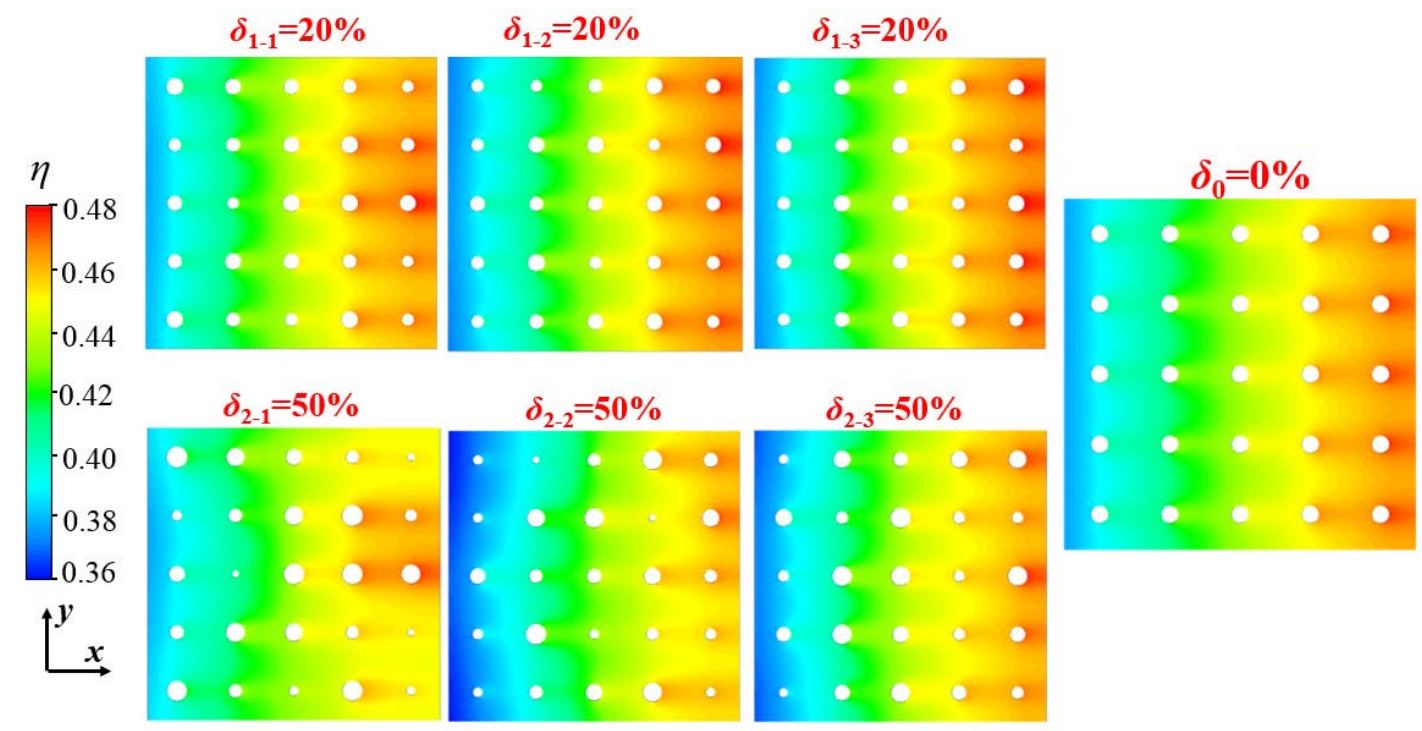

Figure 9. Cooling efficiency distributions for different random distribution ways of inhomogeneous porosity 
Table 1. $\Delta A_{h}, \bar{\eta}, \Delta \bar{\eta}$, and $\Delta \eta_{\max }$ for different random distribution ways

\begin{tabular}{cccccccc}
\hline & $\begin{array}{c}\text { Non- } \\
\text { uniformity }\end{array}$ & $\Delta A_{h}$ & $\begin{array}{c}\text { Injection } \\
\text { ratio }\end{array}$ & $\begin{array}{c}\text { Blowing } \\
\text { ratio }\end{array}$ & $\bar{\eta}$ & $\Delta \bar{\eta}$ & $\Delta \eta_{\max }$ \\
\hline$\delta_{0}$ & $0 \%$ & $0 \%$ & $1 \%$ & 0.20 & $43.09 \%$ & - & - \\
$\delta_{1-1}$ & $20 \%$ & $5.91 \%$ & $1 \%$ & 0.19 & $43.23 \%$ & $0.14 \%$ & $0.81 \%$ \\
$\delta_{1-2}$ & $20 \%$ & $-1.66 \%$ & $1 \%$ & 0.21 & $43.05 \%$ & $0.04 \%$ & $0.87 \%$ \\
$\delta_{1-3}$ & $20 \%$ & $5.39 \%$ & $1 \%$ & 0.19 & $43.24 \%$ & $0.15 \%$ & $0.76 \%$ \\
$\delta_{2-1}$ & $50 \%$ & $20.81 \%$ & $1 \%$ & 0.16 & $42.52 \%$ & $0.57 \%$ & $2.43 \%$ \\
$\delta_{2-2}$ & $50 \%$ & $0.05 \%$ & $1 \%$ & 0.20 & $42.20 \%$ & $0.89 \%$ & $3.55 \%$ \\
$\delta_{2-3}$ & $50 \%$ & $16.68 \%$ & $1 \%$ & 0.17 & $42.31 \%$ & $0.78 \%$ & $2.91 \%$ \\
\hline
\end{tabular}

\subsection{The mechanism of the effect of non-uniformity on cooling efficiency}

The inhomogeneous porosity had a direct influence on the coolant mass flux distributions in holes. The inhomogeneous coolant mass flux distributions then affected the cooling efficiency. Figure 10 shows mass flux ratio distributions in each holes and cooling efficiency distributions along the lines near the holes. The detail lines positions and their corresponding numbers were showed in Fig. 10 (6). The gaps between the curves represented the holes. The coolant mass flux ratio, $M$, was defined as:

$$
M_{i, j}=\frac{m_{i, j}}{M_{\infty}}
$$

We could find the coolant allocation situation in the inhomogeneous holes according to the distributions of $M$. Figure 10 reveals the interaction between nonuniformities of the porosity, the coolant mass flux and the cooling efficiency. The coolant mass flux ratio distributions with inhomogeneous porosities ( $\delta=20 \%$ or $50 \%$ ) were significantly different from that with homogeneous porosity $(\delta=0 \%)$. The deviation of hole size resulted in a deviation of coolant mass flux ratio. The larger hole usually had a higher mass flux ratio, and vice versa. The pressure in the mainstream 
zone decreased along the flow direction due to the pressure drop in the mainstream channel. Thus, the coolant mass flux ratio of the effusion hole in the downstream zone is always higher than the upstream zone even though the hole sizes are the same when $\delta=0 \%$ as shown in Fig. 10 . Thus, although the second hole in line 1 is slightly smaller than the first hole when $\delta=20 \%$ and $50 \%$, the coolant mass flux ratio of the second hole was still slightly higher than the first hole as shown in Fig. 10-(1). Similar phenomenon was also observed in the second and third holes in line 4 when $\delta=20 \%$ and $50 \%$ as shown in Fig. 10-(4). The deviation of coolant mass flux ratio became more significant when the non-uniformity increased from $20 \%$ to $50 \%$, which then resulted in a more significant deviation of cooling efficiency.

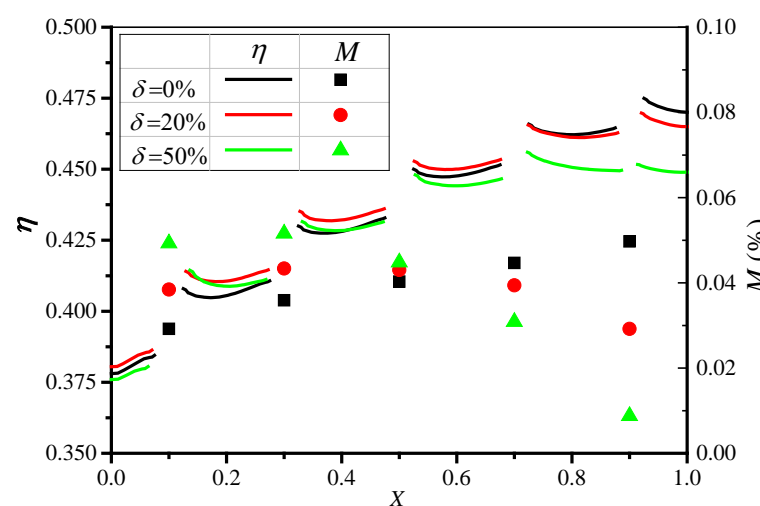

(1) Line 1

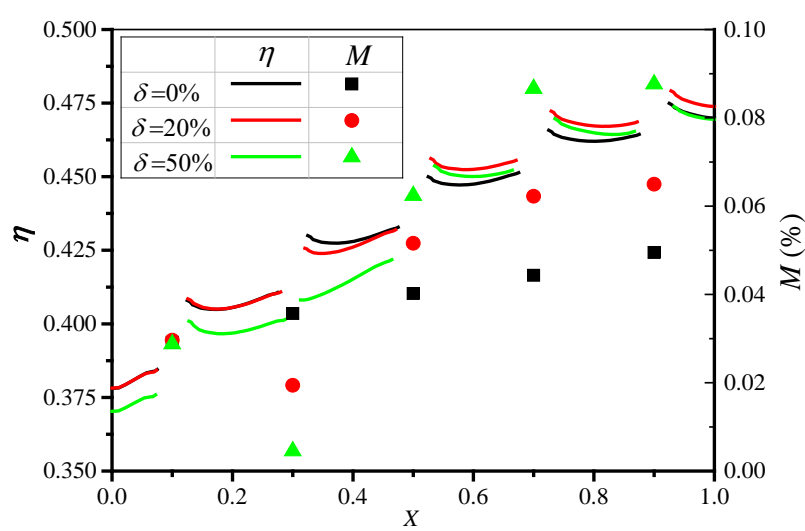

(3) Line 3

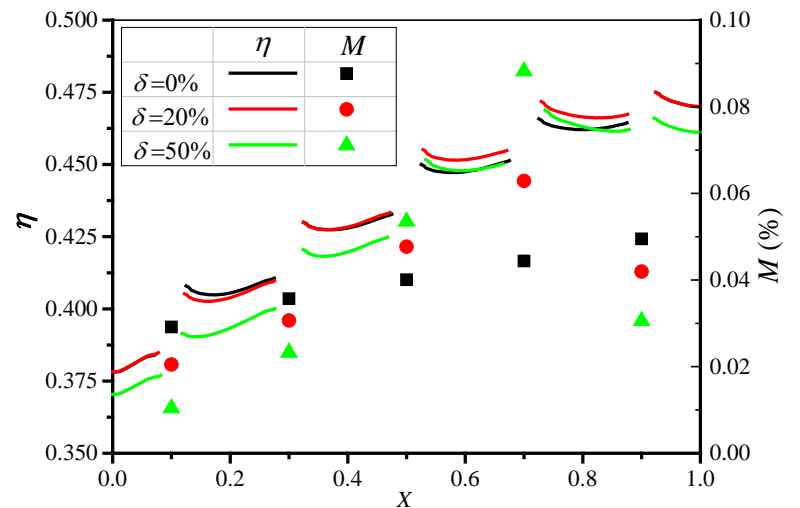

(2) Line2

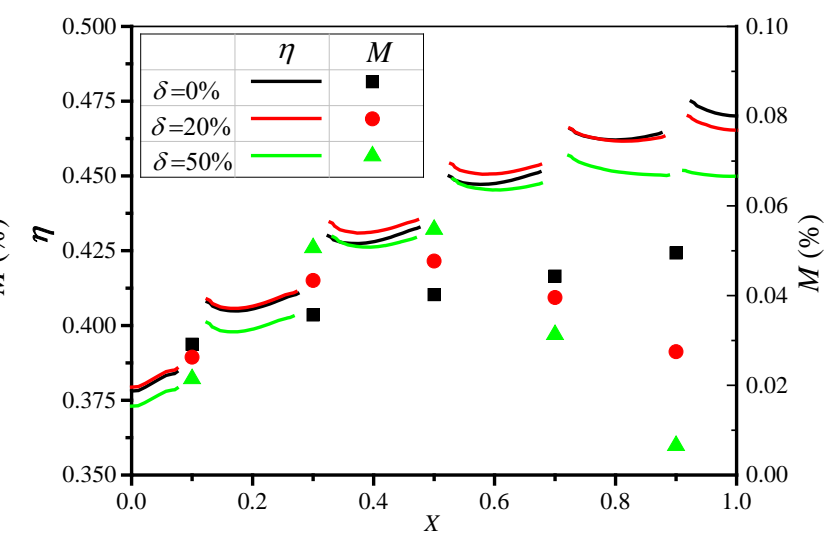

(4) Line 4 


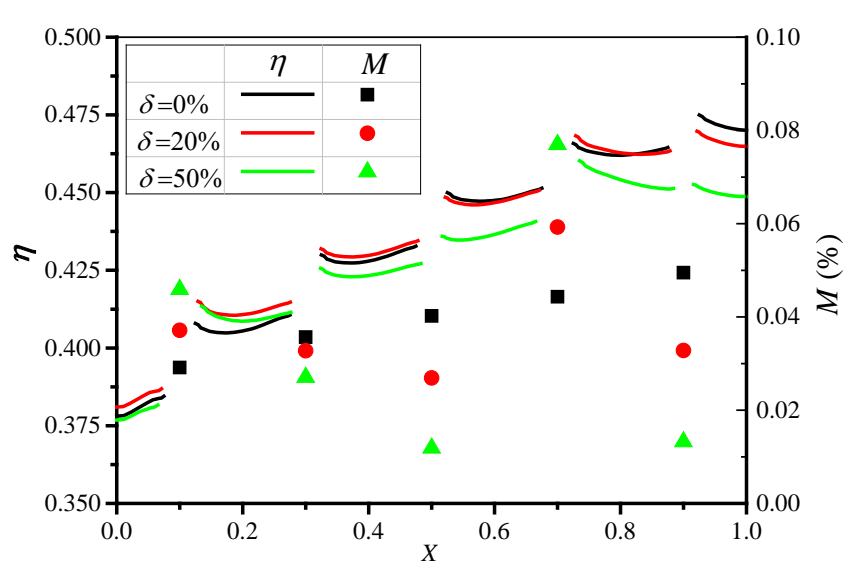

(5) Line 5

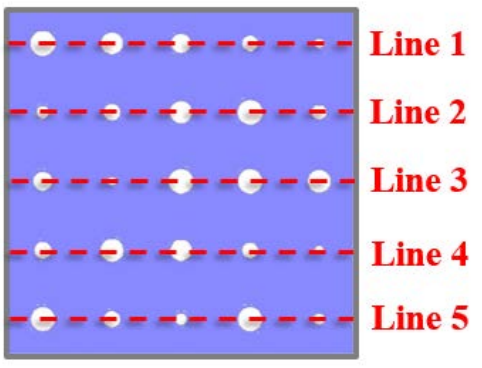

(6) Corresponding numbers of lines

Figure 10. Mass flux ratio distributions and cooling efficiency distributions along the horizontal lines passed holes

The inhomogeneous porosity led to inhomogeneous coolant mass flux distributions. The inhomogeneous coolant mass flux then affected the effusion cooling efficiency by two ways: (1) Affecting the film cooling effect on the porous surface; (2) Affecting the internal convection cooling in the holes.

The adiabatic cooling effect was applied to evaluate the cooling effect of the film on the porous surface [33]. The solid zone in the numerical model was deleted to erase the heat conduction and heat convection in the porous sample. The porous sample was cooled only by the film on the porous surface. The adiabatic cooling efficiency was defined as [33]:

$$
\eta_{a w}=\frac{T_{\infty}-T_{a w}}{T_{\infty}-T_{c}}
$$

In this condition, there is no heat conduction, no heat flux and no heat convection in the porous plate. Thus, the adiabatic cooling efficiency only presents the cooling effect of the film layer. Figure 11 shows the adiabatic cooling efficiency distributions for $\delta=0 \%$ and 20\%. A wider film layer formed beyond a larger hole, which then resulted in a better 
cooling effect. The average adiabatic cooling efficiency was only about $17 \%$. The maximum local difference of adiabatic cooling efficiency between $\delta=0 \%$ and $\delta=20 \%$ reached as high as $\Delta \eta_{\max }=41.5 \%$. The zones with significant local cooling differences had shapes of paired wings as shown in the right picture in Fig. 11. The inhomogeneous porosity had a dramatically influence on the local film cooling effect.
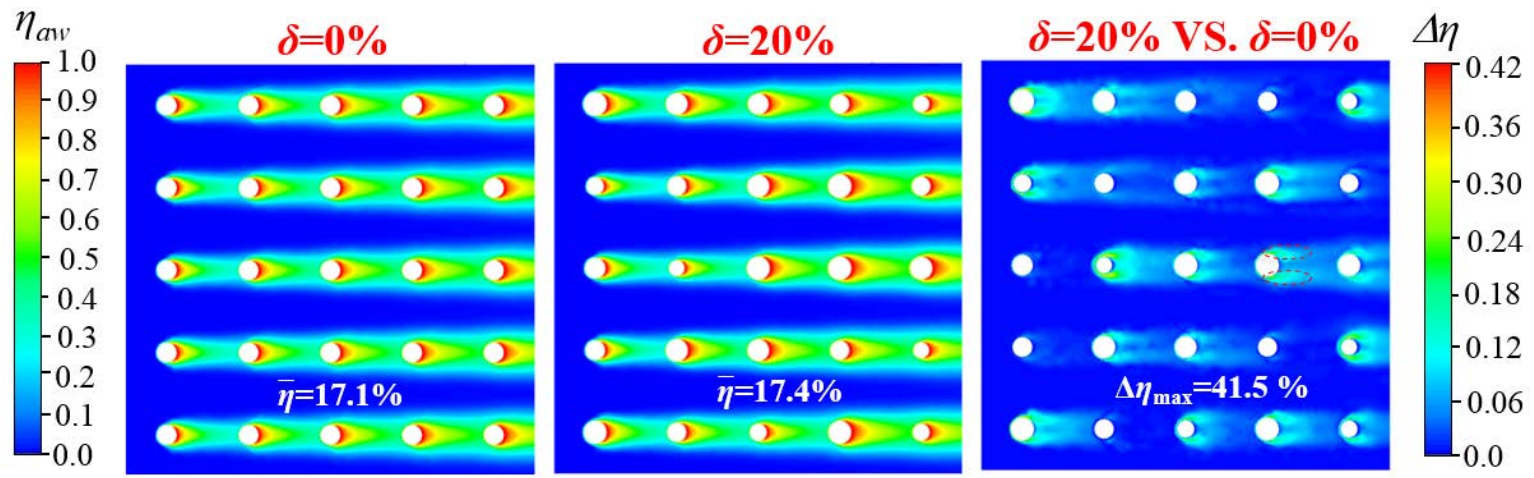

Figure 11. Adiabatic cooling efficiency distributions

The internal cooling in the holes also played an important role for the effusion cooling. Wu and Little [34] put forward the empirical correlations of heat convection in the micro-channel:

$$
N u=0.00222 \operatorname{Pr}^{0.4} \operatorname{Re}^{1.09}
$$

Equation (10) shows that the internal convection cooling intensity was approximately linear to the Reynold number. Thus, the convection cooling intensity in the holes was positive to the coolant mass flow rate and hole size. The internal convection cooling intensity in a hole would markedly decrease with decreasing the Reynold number. We could approximately calculate the difference of convection cooling intensity in holes between $\delta=20 \%$ and $0 \%$ according to Eq. (10).

Table 2 lists the maximum difference percentage of the hole sizes $\Delta D_{\max }$, mass flow 
ratios $\Delta M_{\max }$, film cooling efficiency $\Delta \eta_{\text {aw_max }}$, and internal convection cooling intensity in holes $\Delta N u_{\max }$ for $\delta=20 \%$ compared to the ideal homogeneous sample $\delta=0 \%$. The inhomogeneous porosity $\delta=20 \%$ had considerable influences on film cooling effect and internal cooling intensity, while the maximum local differences of surface film cooling and internal cooling intensity reached $41.5 \%$ and $34.5 \%$ respectively. However, the maximum differences of local and average effusion cooling efficiency were only $0.81 \%$ and $0.14 \%$ respectively.

Table 2. The $\Delta D_{\max }, \Delta M_{\max }, \Delta \eta_{\mathrm{aw} \_\max }$, and $\Delta N u_{\max }$ between $\delta=20 \%$ and $0 \%$

\begin{tabular}{ccccccc}
\hline & $\Delta D_{\max }$ & $\Delta M_{\max }$ & $\Delta \eta_{\text {aw } \max }$ & $\Delta N u_{\max }$ & $\Delta \eta_{\max }$ & $\Delta \bar{\eta}$ \\
\hline$\delta=20 \%$ VS. $\delta=0 \%$ & $19.6 \%$ & $45.5 \%$ & $41.5 \%$ & $34.5 \%$ & $0.81 \%$ & $0.14 \%$ \\
\hline
\end{tabular}

Heat conduction inside the solid played an important role to reduce the influence of inhomogeneous porosity. Although the inhomogeneous porosity made the film cooling effect and internal cooling intensity significantly inhomogeneous, the heat conduction between the holes largely homogenize the cooling efficiency. The heat tended to flow from high temperature to low temperature through the heat conduction, which gave a more uniform distributions of temperature and cooling efficiency. Thus, the inhomogeneous porosity finally had a very slight influence on cooling efficiency when $\delta=20 \%$. The total heat conduction between two adjacent holes was:

$$
Q=\frac{\alpha \lambda A_{C}\left(T_{1}-T_{2}\right)}{\Delta}=\alpha \frac{T_{1}-T_{2}}{R}
$$

Where $T_{1}$ and $T_{2}$ are the temperatures around two adjacent holes. $R$ is the heat resistant, which was a key parameter affecting heat conduction between holes: 


$$
R=\frac{\Delta}{\lambda A_{C}}
$$

Theoretically, a smaller value of $R$ would lead to a more uniform temperature and cooling efficiency distributions owing to the more intensive heat conduction. The next sections will focus on the effects of thermal conductivity, spacing distance and crossing section area, which are related to $R$.

\subsection{Effect of thermal conductivity, spacing distance and crossing section area}

The current materials for additive manufactured gas turbine blades are mainly high-temperature alloy. The most common alloy material of additive manufacturing for gas turbine is Inconel 718 [35] with a thermal conductivity around $11 \mathrm{~W} /(\mathrm{m} \cdot \mathrm{K})$ [36]. In recent years, NASA carried out a research on applying ceramic materials to fabricate gas turbine by additive manufacturing method [37]. Ceramic materials were lightweight, high-temperature-resistant and also had a much lower thermal conductivity compared to metal materials. The effect of thermal conductivity on cooling efficiency with inhomogeneous porosity was studied in this section.

Figure 12 shows cooling efficiency distributions for $\lambda_{1}=1 \mathrm{~W} /(\mathrm{m} \cdot \mathrm{K}), \lambda_{2}=11 \mathrm{~W} /(\mathrm{m} \cdot \mathrm{K})$ and $\lambda_{3}=50 \mathrm{~W} /(\mathrm{m} \cdot \mathrm{K})$. The cooling efficiency of $\delta=20 \%$ was then compared to $\delta=0 \%$. The local absolute cooling efficiency differences were also showed in Fig. 13. The thermal conductivity had a significant influence on effusion cooling. The cooling efficiency distributions became more homogeneous when increasing the thermal conductivity. The difference of cooling efficiency between the front part and the tail part also reduced with increasing the thermal conductivity. The average cooling efficiency significant decreased with decreasing the thermal conductivity. The cooling efficiency reduced 
from $43 \%$ at $\lambda_{3}=50 \mathrm{~W} /(\mathrm{m} \cdot \mathrm{K})$ to $38 \%$ at $\lambda_{1}=1 \mathrm{~W} /(\mathrm{m} \cdot \mathrm{K})$. The local high cooling efficiency zone mainly concentrated near the holes when $\lambda_{1}=1 \mathrm{~W} /(\mathrm{m} \cdot \mathrm{K})$. The coolant could not be fully utilized owing to the large heat resistance, which result in a lower cooling efficiency when $\lambda_{1}=1 \mathrm{~W} /(\mathrm{m} \cdot \mathrm{K})$. The local absolute difference became more significant when decreasing the thermal conductivity as shown in the bottom-row pictures of Fig.12. The maximum local absolute difference of cooling efficiency reached $5.6 \%$ when $\lambda=1$ $\mathrm{W} /(\mathrm{m} \cdot \mathrm{K})$, while only $0.24 \%$ when $\lambda=50 \mathrm{~W} /(\mathrm{m} \cdot \mathrm{K})$. The large heat resistance significantly restrained the heat conduction between the holes. Thus, the deviation of cooling efficiency caused by the inhomogeneous porosity were more difficult to be homogenized when the thermal conductivity was small.

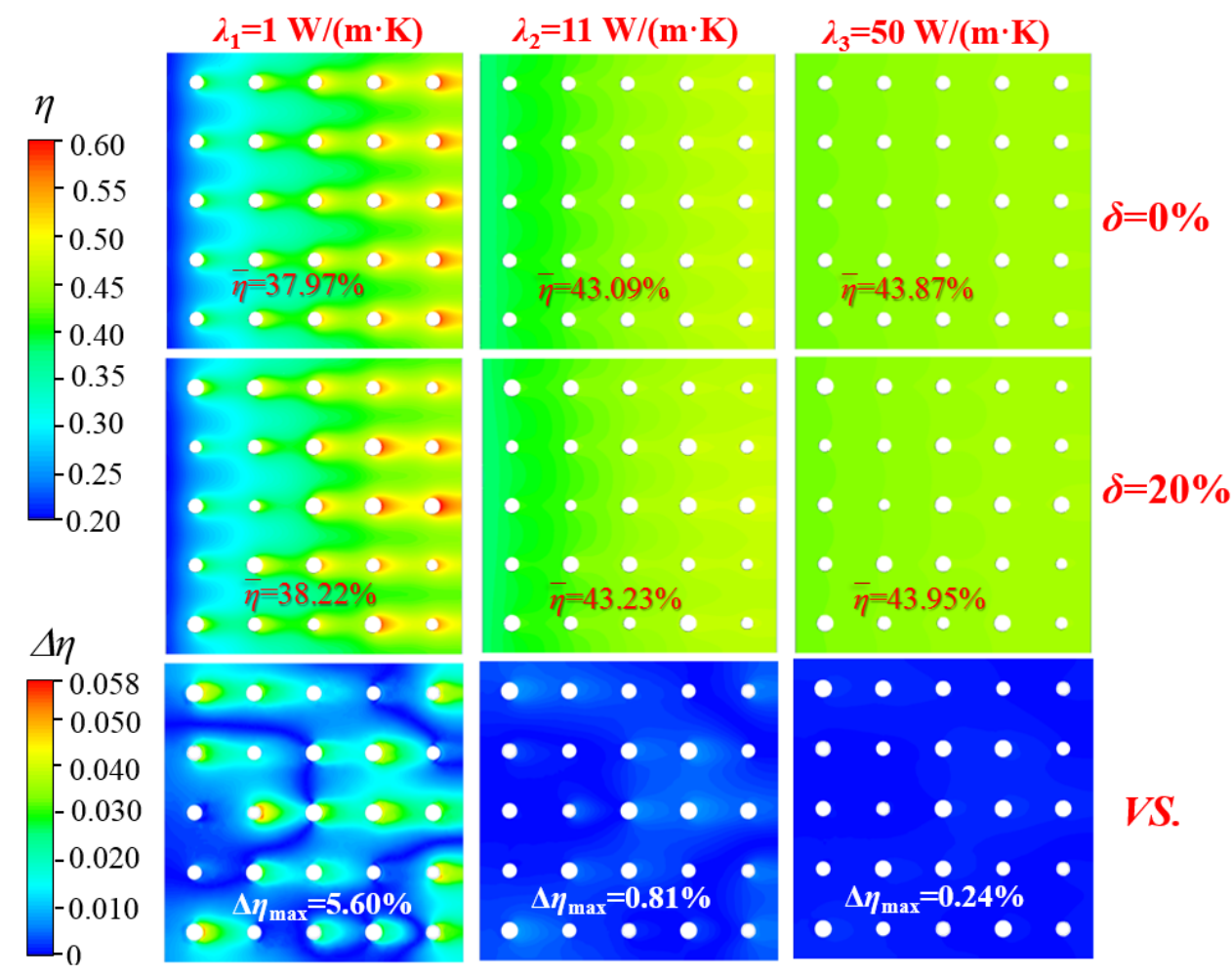

Figure 12. Cooling efficiency distributions for different thermal conductivities

Figure 13 shows coolant mass flux ratio distributions and cooling efficiency distributions along the middle line for different thermal conductivities. The thermal 
conductivity had slight influence on coolant mass flux distributions. The coolant mass flux ratios in each holes nearly had no change when increasing the thermal conductivity form $1 \mathrm{~W} /(\mathrm{m} \cdot \mathrm{K})$ to $50 \mathrm{~W} /(\mathrm{m} \cdot \mathrm{K})$. The cooling efficiency distributed extreme inhomogeneous when $\lambda=1 \mathrm{~W} /(\mathrm{m} \cdot \mathrm{K})$. The cooling efficiency behind the holes significantly higher than other parts. The cooling efficiency curves of $\delta=0 \%$ and $\delta=20 \%$ nearly coincided with each other when $\lambda=50 \mathrm{~W} /(\mathrm{m} \cdot \mathrm{K})$ as shown in Fig.13 (3). The high thermal conductivity benefitted for reducing the influence of inhomogeneous porosity on cooling effect. We should be careful for the inhomogeneous problem when using the low-thermal-conductivity ceramic materials for fabricating gas turbine blades. Applying material with a high thermal conductivity is benefit for eliminating the bad influence of the inhomogeneous porosity on cooling efficiency.

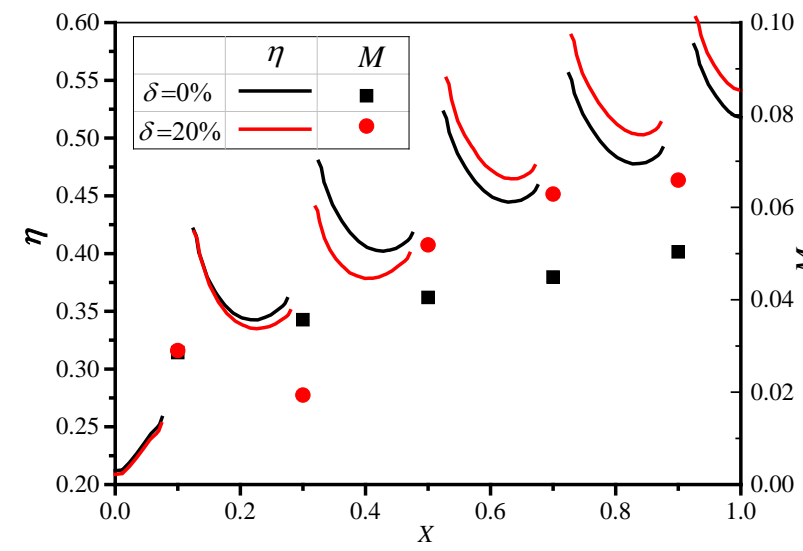

(1) $\lambda=1 \mathrm{~W} /(\mathrm{m} \cdot \mathrm{K})$

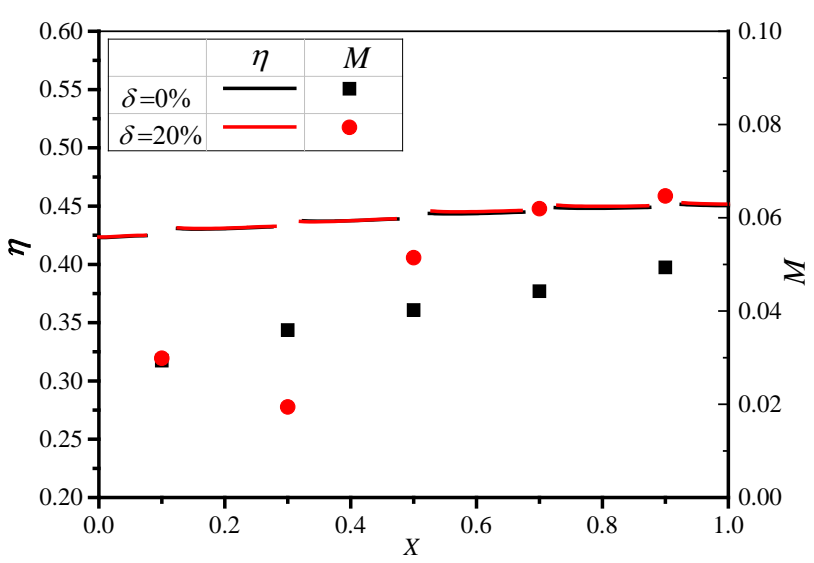

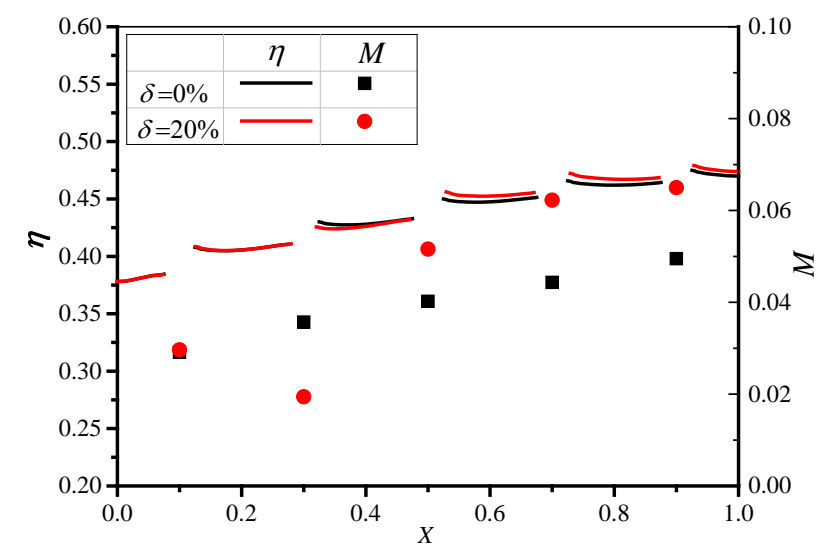

(2) $\lambda=11 \mathrm{~W} /(\mathrm{m} \cdot \mathrm{K})$

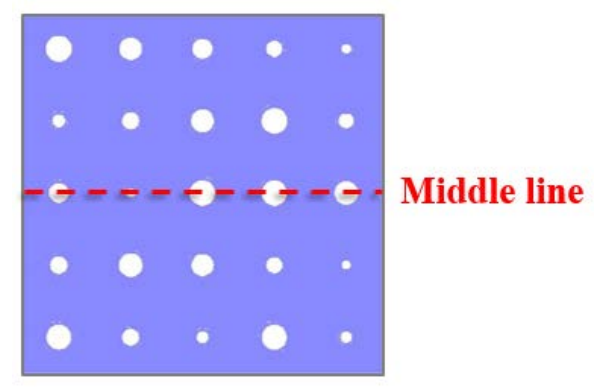


(3) $\lambda=50 \mathrm{~W} /(\mathrm{m} \cdot \mathrm{K})$

Figure 13. Coolant mass flux ratio distributions and cooling efficiency distributions along the middle line for different thermal conductivity

Figure 14 shows local absolute differences of cooling efficiencies for three groups of porous samples. The cooling efficiencies for $\delta=0 \%$ and $\delta=20 \%$ were calculated and then compared to get the local absolute differences in each groups as shown in Fig. 14. The first group had a thickness of $H=5 \mathrm{~mm}$ and a spacing of $\Delta=4 \mathrm{~mm}$. Based on the first group, the second group kept the spacing of $\Delta=4 \mathrm{~mm}$ but reduced the thickness to $H=2$ mm, while the third group kept the thickness of $H=5 \mathrm{~mm}$ but reduced the spacing to $\Delta=2 \mathrm{~mm}$. Only quarter size was applied in the simulation in the third group for saving the calculation. The mainstream condition and coolant injection ratio kept the same for each groups. The local absolute differences increased with decreasing the thickness as shown in Fig.14. The effective cross section area for horizontal heat conduction decreased and the heat resistance increased with decreasing the thickness. Thus, the maximum local absolute difference $\Delta \eta_{\max }$ increased from $0.81 \%$ to $1.14 \%$ when decreasing the thickness from $H=5 \mathrm{~mm}$ to $H=2 \mathrm{~mm}$. The local absolute differences decreased from $0.81 \%$ to $0.59 \%$ with decreasing the holes spacing from $4 \mathrm{~mm}$ to $2 \mathrm{~mm}$ as shown in-Fig.16_Fig. 14. The narrower spacing was benefit for heat conduction between holes. 

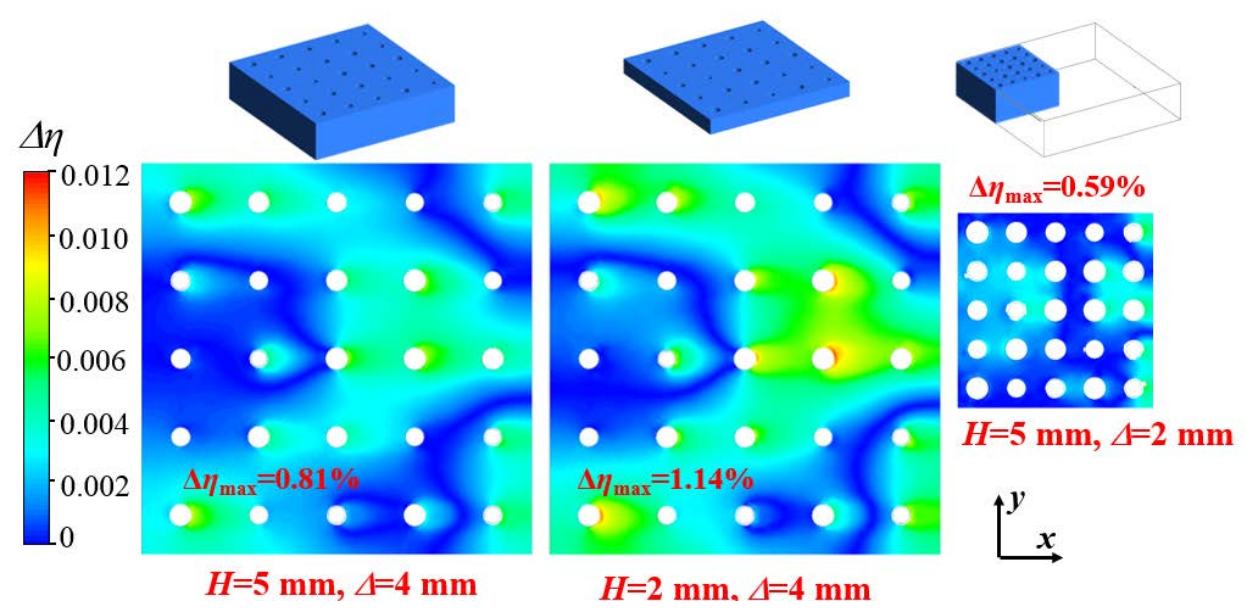

Figure 14. Local absolute differences of cooling efficiencies for different thickness and spacing

Overall, increasing the thermal conductivity, increasing the thickness or decreasing the holes spacing are both benefited for reducing the heat resistance, which resulted in reducing the inhomogeneous effect. Although the inhomogeneous porosity originally had significant influences on film cooling and internal convection cooling, the intensive heat conduction effectively eliminated the bad influence of inhomogeneous porosity.

\subsection{The influence of Thermal Barrier Coatings}

TBC was a widely applied technology to protect blade surfaces from ablation, which enables gas turbines operated in a higher entrance temperature. Min et al. [26] have proposed a method to fabricate TBC on the surfaces of gas turbine blades by additive manufacturing technology. Their experimental results demonstrated that additive manufacturing has the capability to fabricate TBC for turbine airfoils. Refractory-oxide ceramic was the most common material as TBC, such as Yttria Stabilized Zirconia (YSZ), $\mathrm{ZrO}_{2}$ and $\mathrm{Al}_{2} \mathrm{O}_{2}$. The thin TBC layer usually had a very low thermal conductivity while the substrate alloy material had a much higher thermal 
conductivity. The heat transfer was complicate in this double layer structure with a great difference of thermal conductivities.

Figure 15 showed the cooling efficiency distributions for the porous plates without and with TBC. The cooling efficiency distributions presented in the Fig. 15 are above the TBC layer when the porous surface covered with a TBC. The TBC was $0.2-\mathrm{mm}-$ thick with a thermal conductivity of $2 \mathrm{~W} /(\mathrm{m} \cdot \mathrm{K})$. The substrate was 5 -mm-thick with a thermal conductivity of $11 \mathrm{~W} /(\mathrm{m} \cdot \mathrm{K})$. The average cooling efficiencies for $\delta=0 \%$ and $20 \%$ were $43.09 \%$ and $43.23 \%$ without the TBC, while $43.18 \%$ and $42.79 \%$ with a TBC layer. The inhomogeneous porosity had a slight influence on average cooling efficiency when a TBC covered on the surface. However, the maximum local difference of cooling efficiency significantly increased from $0.81 \%$ without the TBC to $4.06 \%$ with the TBC. The thin TBC layer led to a more significant local difference of cooling efficiency between $\delta=0 \%$ and $20 \%$. Table 3 shows the average and maximum local differences of cooling efficiency when the thermal conductivity of TBC further decreased from 2 $\mathrm{W} /(\mathrm{m} \cdot \mathrm{K})$ to $0.5 \mathrm{~W} /(\mathrm{m} \cdot \mathrm{K})$. The inhomogeneous porosity had a slight influence on average cooling efficiency with a difference of $0.38 \%$ when the thermal conductivity of TBC decreased to $0.5 \mathrm{~W} /(\mathrm{m} \cdot \mathrm{K})$. However, the inhomogeneous porosity had a more significant influence on local cooling efficiency when decreasing the thermal conductivity of TBC. The maximum local difference of cooling efficiency increased from $4.06 \%$ to $11.09 \%$ when the thermal conductivity of TBC decreased from $2 \mathrm{~W} /(\mathrm{m} \cdot \mathrm{K})$ to $0.5 \mathrm{~W} /(\mathrm{m} \cdot \mathrm{K})$. 

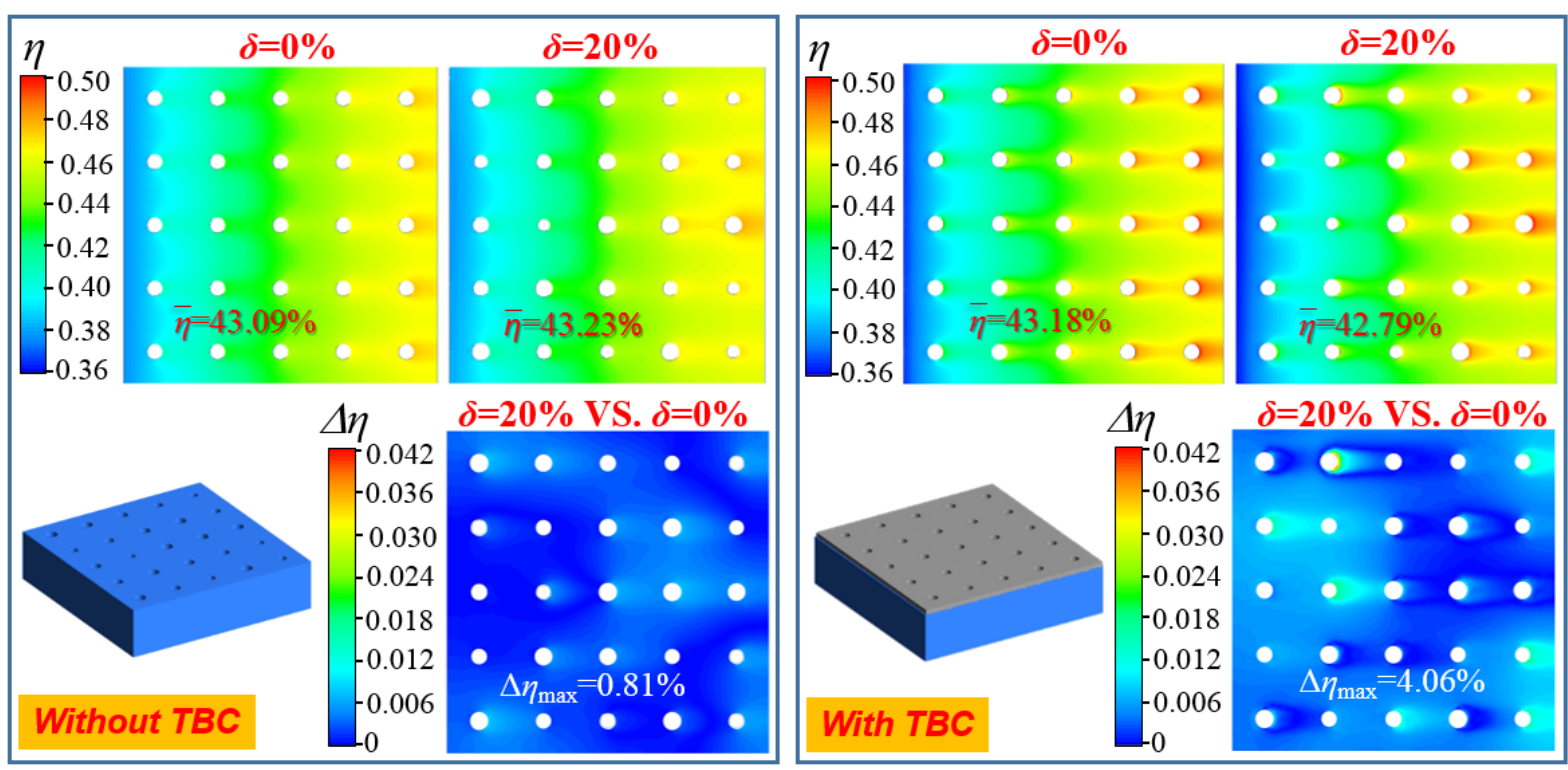

Figure 15. Cooling efficiency distributions for the porous plates without and with a TBC

Table 3. $\bar{\eta}, \Delta \bar{\eta}$, and $\Delta \eta_{\max }$ for different thermal conductivities of the TBC

\begin{tabular}{|c|c|c|c|c|c|}
\hline TBC property & $\delta$ & $\Delta A_{h}$ & $\bar{\eta}$ & $\Delta \bar{\eta}$ & $\Delta \eta_{\max }$ \\
\hline \multirow{2}{*}{ No TBC } & $0 \%$ & 0 & $43.09 \%$ & \multirow{2}{*}{$0.14 \%$} & \multirow{2}{*}{$0.81 \%$} \\
\hline & $20 \%$ & $5.91 \%$ & $43.23 \%$ & & \\
\hline \multirow{2}{*}{$2 \mathrm{~W} /(\mathrm{m} \cdot \mathrm{K})$} & $0 \%$ & 0 & $43.18 \%$ & \multirow{2}{*}{$0.39 \%$} & \multirow{2}{*}{$4.06 \%$} \\
\hline & $20 \%$ & $5.91 \%$ & $42.79 \%$ & & \\
\hline \multirow{2}{*}{$0.5 \mathrm{~W} /(\mathrm{m} \cdot \mathrm{K})$} & $0 \%$ & 0 & $42.28 \%$ & \multirow{2}{*}{$0.38 \%$} & \multirow{2}{*}{$11.09 \%$} \\
\hline & $20 \%$ & $5.91 \%$ & $41.90 \%$ & & \\
\hline
\end{tabular}

The results in the previous section declared that the heat conduction of the substrate solid contributed to eliminate the adverse influence of inhomogeneous porosity. However, the low-thermal-conductivity TBC significantly impeded the homogenizing effect of heat conduction even though the TBC was extremely thin. Figure $17 \underline{16}$ shows the thermal resistance network between adjacent holes without and with a TBC. When there is no TBC, the thermal resistance between the adjacent holes $R_{1}$ was small owing to the high thermal conductivity of the metal material. When a TBC covered on the 
surface, significant additional thermal conductivity was brought into the structure. The horizontal heat resistance $R_{2}$ was very large in the thin and low-thermal-conductivity TBC layer according to Eq. (5). The heat preferred to vertically transfer through the TBC into the substrate. Therefore, TBC introduced considerable additional thermal resistances $2 R_{3}$, which blocked the heat transfer between adjacent holes. Thus, the significant local difference of surface film cooling effect caused by inhomogeneous porosity was more difficult to be homogenized when coating with a TBC layer. We should be aware of that the non-uniform temperature distributions in TBC layer could generate local thermal stress which probably led to cracking-off and abscission of TBC.

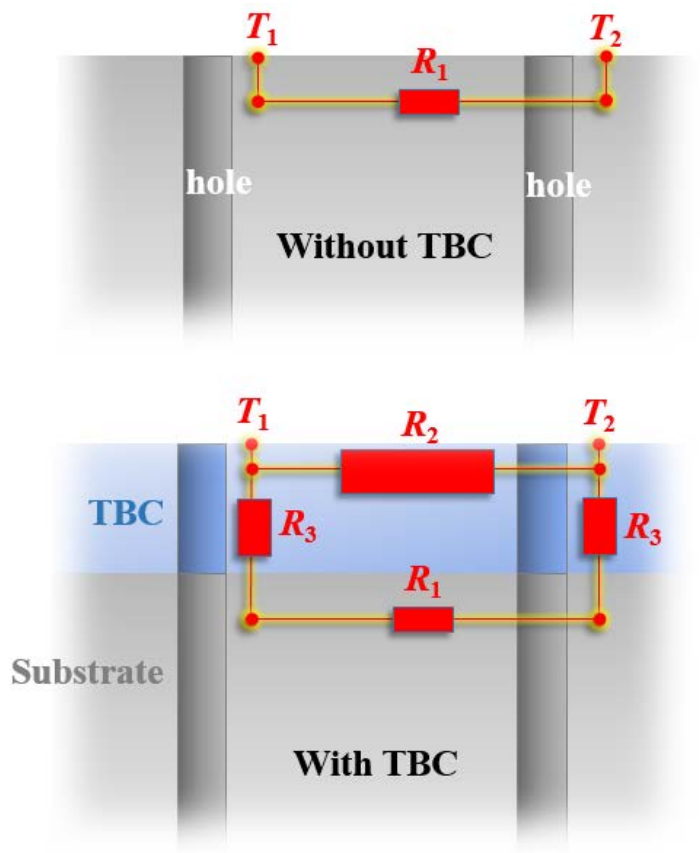

Figure 1716. Thermal resistance network between adjacent holes without and with TBC

\section{Conclusions}

This study numerically investigated the inhomogeneous problem on effusion 
cooling, which could occur in the additive manufactured gas turbine blades. The effects of non-uniformity, thermal conductivity, thickness, holes spacing and TBC were investigated. The main results are:

(1) The inhomogeneous porosity had significant influents on the cooling effects of the surface film and internal holes. The local cooling efficiencies of the film and internal holes maximally changed $41.5 \%$ and $34.5 \%$ respectively under the influence of the $20 \%$ non-uniformity. However, the $20 \%$ non-uniformity had a very slight effect on both global and local cooling efficiency owing to the heat conduction effect. The maximum absolute differences of average and local cooling efficiency between $\delta=20 \%$ and $\delta=0 \%$ were only $0.14 \%$ and $0.81 \%$ respectively. The influence of inhomogeneous porosity on effusion cooling could be ignored if controlling the hole precision of additive manufacturing less than $20 \%$. The inhomogeneous porosity had a more significant influence on cooling efficiency when the non-uniformity further increased to 50\%. However, the difference of average cooling efficiency was also only $\Delta \bar{\eta}=0.57 \%$ even when $\delta=50 \%$.

(2) Heat conduction inside the solid played an important role to reduce the influence of inhomogeneous porosity. Increasing the thermal conductivity, increasing the thickness or decreasing the holes spacing both contributed to reduce the heat resistance, which resulted in reducing the inhomogeneous effect. Increasing the thermal conductivity had the most significant effect for eliminating the influence of inhomogeneous porosity on cooling efficiency.

(3) The inhomogeneous porosity had a remarkable effect on effusion cooling 
efficiency when a low-thermal-conductivity Thermal Barrier Coating (TBC) covered on the surface. The TBC introduced considerable additional thermal resistances even though it was very thin. Decreasing the thermal conductivity of TBC would further exacerbate the inhomogeneous problem.

\section{Acknowledgments}

We thank computing facilities in Osney lab of University of Oxford. We are also grateful for the support of the Zijing scholar fellowship. We also thank Dr. Jingyuan Xu for some valuable suggestions on this work.

\section{Nomenclature}

A Surface area of the sample $\left[\mathrm{m}^{2}\right]$

$A_{h} \quad$ Opening (holes) area of the sample $\left[\mathrm{m}^{2}\right]$

$A_{C} \quad$ Cross section area for heat conduction between two holes

$D_{0} \quad$ Ideal designed value of the hole diameter [mm]

$D_{i, j} \quad$ Actual values of the hole diameters [mm]

F Coolant injection ratio

$H \quad$ Thickness [m]

i $\quad$ Abscissas of a hole

$j \quad$ Ordinates of a hole 
L $\quad$ Length [m]

$m_{i, j} \quad$ Mass flow rate in a certain hole [kg/s]

$M_{\infty} \quad$ Mass flow rate of the mainstream [kg/s]

$M_{i, j} \quad$ Coolant mass flux ratio of a certain hole

$\mathrm{Nu} \quad$ Nusselt number

$N_{x} \quad$ Number of rows of holes at the $x$ direction

$N_{y} \quad$ Number of rows of holes at the $y$ direction

$P \quad$ Pressure $[\mathrm{Pa}]$

$\operatorname{Pr} \quad$ Prandtl number

$R \quad$ Heat resistant [K/W]

Re Reynold number

$T \quad$ Temperature $[\mathrm{K}]$

$T_{\mathrm{aw}} \quad$ Temperature of adiabatic wall [K]

$T_{\mathrm{C}} \quad$ Temperature of coolant $[\mathrm{K}]$

$T_{\mathrm{w}} \quad$ Temperature of porous surface [K]

$T_{\infty} \quad$ Temperature of mainstream $[\mathrm{K}]$

$V \quad$ Velocity $[\mathrm{m} / \mathrm{s}]$

$V_{\mathrm{C}} \quad$ Equivalent average velocity of the coolant on the porous surface $[\mathrm{m} / \mathrm{s}]$

$V_{\infty} \quad$ Velocity of the mainstream [m/s]

W $\quad$ Width $[\mathrm{m}]$ 


\section{Greek symbols}

$\alpha \quad$ Correction factor of heat conduction between two holes

$\Delta \quad$ Spacing of holes [m]

$\delta \quad$ Non-uniformity

$\rho \quad$ Density $\left[\mathrm{Kg} / \mathrm{m}^{3}\right]$

$\rho_{c} \quad$ Density of the inlet coolant $\left[\mathrm{Kg} / \mathrm{m}^{3}\right]$

$\rho_{\infty} \quad$ Density of the mainstream $\left[\mathrm{Kg} / \mathrm{m}^{3}\right]$

$\varepsilon \quad$ Porosity

$\Delta \varepsilon \quad$ The relative change of the porosity

$\eta \quad$ Effusion cooling efficiency

$\bar{\eta} \quad$ Average cooling efficiency

$\eta_{0} \quad$ Effusion cooling efficiency with a homogeneous porosity

$\eta_{\text {aw }} \quad$ Adiabatic cooling efficiency

$\eta_{\delta} \quad$ Effusion cooling efficiency with a non-uniformity of $\delta$

$\Delta \eta_{\max } \quad$ Maximum local absolute difference of cooling efficiencies

$\Delta \bar{\eta} \quad$ Differences of average cooling efficiencies

$\lambda \quad$ Thermal conductivity of the solid matrix $[\mathrm{W} /(\mathrm{m} \cdot \mathrm{K})]$

\section{Reference}

[1] Han, J. C., Dutta, S., \& Ekkad, S. (2012). Gas turbine heat transfer and cooling technology. CRC Press. 
[2] Boyd, E. J., McClintic, J. W., Chavez, K. F., \& Bogard, D. G. (2017). Direct measurement of heat transfer coefficient augmentation at multiple density ratios. Journal of Turbomachinery, 139(1), 011005.

[3] Krewinkel, R. (2013). A review of gas turbine effusion cooling studies. International Journal of Heat and Mass Transfer, 66, 706-722.

[4] Staniforth, R. (1954). A Theoretical Note on Effusion Cooled Gas Turbine Blades. HM Stationery Office.

[5] Grootenhuis, P. (1959). The mechanism and application of effusion cooling. The Aeronautical Journal, 63(578), 73-89.

[6] Andrews, G. E., Asere, A. A., Gupta, M. L., \& Mkpadi, M. C. (1985, March). Full coverage discrete hole film cooling: the influence of hole size. In ASME 1985 International Gas Turbine Conference and Exhibit (pp. V003T09A003-V003T09A003). American Society of Mechanical Engineers.

[7] Andrews, G. E., Asere, A. A., Mkpadi, M. C., \& Tirmahi, A. (1986). Transpiration cooling: contribution of film cooling to the overall cooling effectiveness. International Journal of Turbo and Jet Engines, 3(2-3), 245-256.

[8] Bohn, D., \& Moritz, N. (2004). Numerical study on inner hole shaping of full coverage cooled multi-layer plates. ISROMAC10, 143.

[9] A. Andreini, A. Ceccherini, B. Facchini, L. Tarchi, L. Toni, Hole spacing effect on adiabatic effectiveness of effusion cooling arrays for turbine endwall application: experimental and numerical results, in: F. Heitmeir, F. Martelli, M. Manna (eds.), Proceedings of the 8th European Turbomachinery Conference, 2009, pp. 553-567. 
[10] Min, Z., Huang, G., Parbat, S. N., Yang, L., \& Chyu, M. K. (2019). Experimental Investigation on Additively Manufactured Transpiration and Film Cooling Structures. Journal of Turbomachinery, 141(3), 031009.

[11] Ngo, T. D., Kashani, A., Imbalzano, G., Nguyen, K. T., \& Hui, D. (2018). Additive manufacturing (3D printing): A review of materials, methods, applications and challenges. Composites Part B: Engineering.

[12] Frazier, W. E. (2014). Metal additive manufacturing: a review. Journal of Materials Engineering and Performance, 23(6), 1917-1928.

[13] Gu, D. D., Meiners, W., Wissenbach, K., \& Poprawe, R. (2012). Laser additive manufacturing of metallic components: materials, processes and mechanisms. International materials reviews, 57(3), 133-164.

[14] Ackland, D. C., Robinson, D., Redhead, M., Lee, P. V. S., Moskaljuk, A., \& Dimitroulis, G. (2017). A personalized 3D-printed prosthetic joint replacement for the human temporomandibular joint: From implant design to implantation. Journal of the mechanical behavior of biomedical materials, 69, 404-411.

[15] Chen, R. K., Jin, Y. A., Wensman, J., \& Shih, A. (2016). Additive manufacturing of custom orthoses and prostheses—a review. Additive Manufacturing, 12, 77-89.

[16] Liu, R., Wang, Z., Sparks, T., Liou, F., \& Newkirk, J. (2017). Aerospace applications of laser additive manufacturing. In Laser Additive Manufacturing (pp. 351371).

[17] How 3D Printing Will Change Manufacturing - GE Reports. https://www.ge.com/ reports/epiphany-disruption-ge-additive-chief-explains-3d-printing-will- 
upendmanufacturing/. 13/10/2017.

[18] 3D Printing is Merged with Printed Electronics (NASDAQ: SSYS). http://investors. stratasys.com/releasedetail.cfm?ReleaseID=659142. 13/10/2017.

[19] 3D Print Canal House - DUS Architects. http://houseofdus.com/project/3dprintcanal-house/. 23/10/2017.

[20] Lim, S., Buswell, R. A., Le, T. T., Austin, S. A., Gibb, A. G., \& Thorpe, T. (2012). Developments in construction-scale additive manufacturing processes. Automation in construction, 21, 262-268.

[21] Navrotsky, V., Graichen, A., \& Brodin, H. (2015). Industrialisation of 3D printing (additive manufacturing) for gas turbine components repair and manufacturing. VGB PowerTech, 12, 48-52.

[22] Gupta, M., Markocsan, N., Rocchio-Heller, R., Liu, J., Li, X. H., \& Östergren, L. (2017). Multilayered suspension plasma sprayed thermal barrier coatings for high temperature gas turbine applications. In International Thermal Spray Conference 2017, June 7-9, Dusseldorf, Germany.

[23] Min, Z., Parbat, S. N., Yang, L., Kang, B., \& Chyu, M. K. (2018). Fabrication and Characterization of Additive Manufactured Nickel-Based Oxide Dispersion Strengthened Coating Layer for High-Temperature Application. Journal of Engineering for Gas Turbines and Power, 140(6), 062101.

[24] Breakthrough with 3D printed Gas Turbine Blades.

https://www.siemens.com/innovation/en/home/pictures-of-the-future/industry-andautomation/additive-manufacturing-3d-printed-gas-turbine-blades.html. 06/02/2017. 
[25] Huang, G., Min, Z., Yang, L., Jiang, P. X., \& Chyu, M. (2018). Transpiration cooling for additive manufactured porous plates with partition walls. International Journal of Heat and Mass Transfer, 124, 1076-1087.

[26] Huang, G., Zhu, Y., Liao, Z., Xu, R., \& Jiang, P. X. (2019). Biomimetic selfpumping transpiration cooling for additive manufactured porous module with tree-like micro-channel. International Journal of Heat and Mass Transfer, 131, 403-410.

[27] Calignano, F., Lorusso, M., Pakkanen, J., Trevisan, F., Ambrosio, E. P., Manfredi, D., \& Fino, P. (2017). Investigation of accuracy and dimensional limits of part produced in aluminum alloy by selective laser melting. The International Journal of Advanced Manufacturing Technology, 88(1-4), 451-458.

[28] Yang, L., Chen, W., \& Chyu, M. K. (2018). A convolution modeling method for pore plugging impact on transpiration cooling configurations perforated by straight holes. International Journal of Heat and Mass Transfer, 126, 1057-1066.

[29] Huang, Z., Xiong, Y. B., Liu, Y. Q., Jiang, P. X., \& Zhu, Y. H. (2015). Experimental investigation of full-coverage effusion cooling through perforated flat plates. Applied Thermal Engineering, 76, 76-85.

[30] Rogers, N., Ren, Z., Buzzard, W., Sweeney, B., Tinker, N., Ligrani, P., ... \& Moon, H. K. (2017). Effects of Double Wall Cooling Configuration and Conditions on Performance of Full-Coverage Effusion Cooling. Journal of Turbomachinery, 139(5), 051009.

[31] Oguntade, H. I., Andrews, G. E., Burns, A. D., Ingham, D. B., \& Pourkashanian, M. (2017, June). Impingement/Effusion Cooling With Low Coolant Mass Flow. In 
ASME Turbo Expo 2017: Turbomachinery Technical Conference and Exposition (pp. V05CT17A004-V05CT17A004). American Society of Mechanical Engineers.

[32] Braian, M., Jönsson, D., Kevci, M., \& Wennerberg, A. (2018). Geometrical accuracy of metallic objects produced with additive or subtractive manufacturing: A comparative in vitro study. Dental Materials, 34(7), 978-993.

[33] Boyd, E. J., McClintic, J. W., Chavez, K. F., \& Bogard, D. G. (2017). Direct measurement of heat transfer coefficient augmentation at multiple density ratios. Journal of Turbomachinery, 139(1), 011005.

[34] Wu, P., \& Little, W. A. (1984). Measurement of the heat transfer characteristics of gas flow in fine channel heat exchangers used for microminiature refrigerators. Cryogenics, 24(8), 415-420.

[35] Thomas, A., El-Wahabi, M., Cabrera, J. M., \& Prado, J. M. (2006). High temperature deformation of Inconel 718. Journal of materials processing technology, 177(1-3), 469-472.

[36] Sweet, J. N., Roth, E. P., \& Moss, M. (1987). Thermal conductivity of Inconel 718 and 304 stainless steel. International journal of thermophysics, 8(5), 593-606.

[37] Mrityunjay Singh, Michael C. Halbig, Joseph E. Grady. Additive Manufacturing of Light Weight Ceramic Matrix Composites For Gas Turbine Engine Applications, 2015, https://ceramics.onlinelibrary.wiley.com/doi/pdf/10.1002/9781119211662.ch16 